\title{
BMJ Open Financial modelling of femtosecond laser-assisted cataract surgery within the National Health Service using a 'hub and spoke' model for the delivery of high-volume cataract surgery
}

\author{
H W Roberts, ${ }^{1,2}$ M Z Ni, ${ }^{3}$ D P S O'Brart ${ }^{1,2}$
}

To cite: Roberts HW, Ni MZ, O'Brart DPS. Financial modelling of femtosecond laser-assisted cataract surgery within the National Health Service using a 'hub and spoke' model for the delivery of high-volume cataract surgery. BMJ Open 2017;7:e013616.

doi:10.1136/bmjopen-2016013616

- Prepublication history for this paper is available online. To view these files please visit the journal online (http://dx.doi.org/10.1136/ bmjopen-2016-013616).

Received 25 July 2016 Revised 31 October 2016 Accepted 23 December 2016

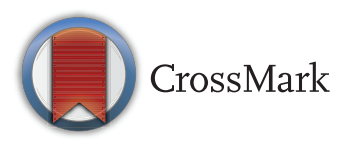

${ }^{1}$ Department of Ophthalmology, Guy's and St Thomas' NHS Foundation

Trust, London, UK

${ }^{2}$ King's College London, London, UK

${ }^{3}$ Division of Surgery, Department of Surgery and Cancer, Imperial College London, St Mary's Hospital, London, UK

Correspondence to Professor D P S O'Brart; davidobrart@aol.com

\section{ABSTRACT}

Aims: To develop financial models which offset additional costs associated with femtosecond laser (FL)-assisted cataract surgery (FLACS) against improvements in productivity and to determine important factors relating to its implementation into the National Health Service (NHS).

Methods: FL platforms are expensive, in initial purchase and running costs. The additional costs associated with $\mathrm{FL}$ technology might be offset by an increase in surgical efficiency. Using a 'hub and spoke' model to provide high-volume cataract surgery, we designed a financial model, comparing FLACS against conventional phacoemulsification surgery (CPS). The model was populated with averaged financial data from $4 \mathrm{NHS}$ foundation trusts and 4 commercial organisations manufacturing $\mathrm{FL}$ platforms. We tested our model with sensitivity and threshold analyses to allow for variations or uncertainties.

Results: The averaged weekly workload for cataract surgery using our hub and spoke model required either 8 or 5.4 theatre sessions with CPS or FLACS, respectively. Despite reduced theatre utilisation, CPS (average $£ 433 /$ case) was still found to be $8.7 \%$ cheaper than FLACS (average £502/case). The greatest associated cost of FLACS was the patient interface (PI) (average £135/case). Sensitivity analyses demonstrated that FLACS could be less expensive than CPS, but only if increased efficiency, in terms of cataract procedures per theatre list, increased by over $100 \%$, or if the cost of the PI was reduced by almost $70 \%$.

Conclusions: The financial viability of FLACS within the NHS is currently precluded by the cost of the PI and the lack of knowledge regarding any gains in operational efficiency.

\section{INTRODUCTION}

In 2014-2015, over 370000 cataract operations were performed on the National Health Service (NHS). ${ }^{1}$ This was 3.7 times the number performed in $1989 .^{2}$ The need

\section{Strengths and limitations of this study}

- Data were collected and collated from four NHS foundation trusts of various sizes, locations and demographics to ensure the conclusions could be more representative.

- This is the only study investigating the financial implications of femtosecond laser-assisted cataract surgery (FLACS) which highlights the significance of the cost of the disposable patient interfaces over the capital cost of the laser machine itself.

- This is the only study investigating the financial implications of FLACS which has developed a working model incorporating a laser to improve, rather than impede productivity.

- This study falls short of providing an incremental cost-effectiveness ratio for FLACS. For the purposes of this model, clinical outcomes are assumed to be equivalent. This is currently supported by the latest evidence.

for cataract surgery is expected to rise further with increasing life expectancy, rising population size, growing patient expectations and an increase in age-related chronic diseases associated with cataracts, such as diabetes. ${ }^{3}$ With current financial constraints, this increased future demand for cataract surgery within the NHS is liable to be problematic.

Femtosecond laser (FL) technology has been recently introduced into cataract surgery in an attempt to automate and improve the efficacy and safety of some of the surgical steps within this procedure. ${ }^{4}$ Within the scientific literature, there are now numerous prospective case series supporting its usage and continued development and more surgeons are adopting this new technology. ${ }^{4-9}$ However, while FL technology undoubtedly offers great surgical precision, a 
recent meta-analysis shows no significant advantages in terms of safety and efficacy of FL-assisted cataract surgery (FLACS) over conventional phacoemulsification cataract surgery (CPS). ${ }^{10}$ Two large multicentre randomised controlled trials (RCTs) are currently underway in France and the UK and may provide further evidence as to whether there is a difference in the clinical outcomes from FLACS. ${ }^{11} 12$

Until evidence exists of improved surgical outcomes, it is difficult at present to support the widespread implementation of FLACS. This is particularly pertinent as the introduction of FLACS has significant associated financial costs. These include initial purchase costs of the FL system itself, servicing, depreciation and the individual patient interfaces (PI), which call into question its financial viability, especially in a state-funded healthcare system. The majority of existing literature on the economics of FLACS originates from healthcare systems within countries such as the USA or Australia, where additional costs from procedures perceived as having a premium status may be passed onto the patient in the form of a copayment system. ${ }^{13-15}$ In these healthcare systems, the existing literature suggests that FLACS is not, at this time, a cost-effective solution. It is not surprising, therefore, that adoption of this technology within the NHS so far has been minimal and largely directed at research rather than service provision.

Despite associated costs, by its very nature, the FL offers the potential to remove several steps of cataract extraction from needing to be performed by a fully trained surgeon in a fully equipped ophthalmic operating theatre. FL technology can automate several surgical steps of the cataract procedure, such as corneal incisions, arcuate keratotomies, capsulotomy and nuclear lens division, all of which can be potentially undertaken with this technology by a doctor in training or suitably trained nurse or technician in a clean room. By reducing the actual amount of time each patient spends within the operating theatre under the care of a trained surgeon, the volume of surgical cases undertaken in a given period of time might potentially be increased. This may be especially true if a 'hub and spoke' model is utilised, with the FL performing these initial automated steps and then allowing the completion of the surgical procedure to be undertaken in more than one operating theatre at a time. If the number of cases per theatre session can be increased sufficiently then the initial expenditure and additional costs associated with FL technology might be offset.

For FLACS to see increased adoption by a state-funded healthcare system such as the NHS, it would need to be shown to be cost-effective based on an acceptable incremental cost-effectiveness ratio (ICER). The ICER is defined by the difference in the cost between two possible interventions divided by the difference in their clinical effectiveness. This study aims to investigate, in the absence of clinical outcomes from large RCTs showing any surgical benefit, the cost of incorporating FLACS into the NHS system in order to determine whether the increased costs of equipment may be offset by an increase in the volume of surgery performed.

\section{METHODS}

Financial model

A financial model was designed to compare FLACS against CPS for the provision of cataract surgery within the NHS. The inputs for this model can be seen in table 1 . The model was based on data from four separate NHS Foundation Trust Ophthalmology Departments (Guy's and St Thomas' NHS Foundation Trust, Norfolk and Norwich NHS Foundation Trust, Peterborough and Stamford NHS Foundation Trust and West Suffolk NHS Foundation Trust) and four manufacturers of commercially available FL devices (Abbott Medical Optics, Santa Ana, California, USA; Ziemer Ophthalmic Systems AG, Switzerland; Alcon Laboratories, Fort Worth, Texas, USA and Bausch \& Lomb, Rochester, New York, USA). The data were collated and averaged to ensure the results were more representative than had just one ophthalmology department or one FL been used.

Values for each input were derived from the following sources.

1. Income for each procedure is reimbursed at the NHS national tariffs for 2014-2015 plus an additional market forces factor. ${ }^{16} 17$

2. Costs were divided into direct labour costs, equipment costs and overheads. Direct labour costs per theatre session were derived from NHS pay scales and midpoint values were chosen. This was then proportioned to the estimated duration of each theatre session.

3. Costs relating to the FL were averaged from those provided by four manufacturers of commercially available FL devices.

4. Costs such as estate, equipment and supplies were averaged from four NHS Foundation Trusts' departmental budgets (2014-2015).

5. Pharmacy and administrative costs were obtained by reviewing the departmental budget at our institution.

6 . Baseline values for the number of cases achievable per 4-hour theatre session were given nominal values of 7 cases for CPS and 10 cases for FLACS. These initial values were then tested using sensitivity and threshold analyses.

The model was tested based on two scenarios: FLACS versus CPS based on an average number of seven cases currently performed on a CPS cataract lists and a FLACS delivery model based on a 'hub and spoke' method with one FL in a clean room and operated by a doctor in training preparing patients for two operating theatres running in parallel with their associated surgeons, nursing and technical support staff.

\section{'Hub and spoke' FLACS model}

Our theoretical 'hub and spoke' model for FLACS is based on a single FL platform in a clean room and 
operated by an ophthalmology registrar or suitably trained allied health professional and supported by a theatre nurse (figure 1). The laser would be programmed to perform capsulotomy, nuclear lens division and arcuate keratotomies (when indicated) for each individual patient. Patients would be prepared for two operating theatres running in parallel with their associated surgeons, nursing and technical support staff. The assumed FL treatment time is a maximum of 10 min per patient allowing for the preparation of up to 20 cataract surgery cases, 10 per theatre per 4-hour operating theatre session. The assumed theatre time is a

\begin{tabular}{|c|c|c|c|c|}
\hline Source & & Input & Value $(£)$ & Range (£) \\
\hline \multicolumn{5}{|l|}{ A } \\
\hline Income & & NHS tariff for cataract surgery & 789 & $729-917$ \\
\hline \multirow[t]{12}{*}{ Expenses } & Staffing (per & Consultant surgeon & 246 & \\
\hline & session) & Band 5 nurse & 79 & \\
\hline & & Registrar/laser technician & 101 & \\
\hline & & Band 6 nurse/laser technician & 102 & \\
\hline & & Ward clerk & 53 & \\
\hline & $\begin{array}{l}\text { Overheads (per } \\
\text { year) }\end{array}$ & Ophthalmic day-case unit & 525620 & $\begin{array}{l}30112- \\
1061481\end{array}$ \\
\hline & & $2 \times$ operating theatres & 585676 & $\begin{array}{l}353245- \\
962287\end{array}$ \\
\hline & Laser & Initial cost & 262500 & $175 \mathrm{k}-350 \mathrm{k}$ \\
\hline & & Maintenance/year & 28333 & $20 \mathrm{k}-35 \mathrm{k}$ \\
\hline & & Cost of patient interface & 134.75 & $99-170$ \\
\hline & Other costs & Disposables and IOL (per case) & 103 & \\
\hline & & $\begin{array}{l}\text { Cost of administration, management and pharmacy } \\
\text { (per case) }\end{array}$ & 50 & \\
\hline \multicolumn{5}{|l|}{ B } \\
\hline \multirow[t]{4}{*}{$\begin{array}{c}\text { Other } \\
\text { variables }\end{array}$} & & Number of cataract operations required per week & $\begin{array}{l}55 \\
\text { operations }\end{array}$ & $27-96$ \\
\hline & & Number of cases on CPS list & 7 operations & \\
\hline & & Number of cases on FLACS list* & $\begin{array}{l}10 \\
\text { operations }\end{array}$ & \\
\hline & & Lifetime of FL & 10 years & \\
\hline
\end{tabular}

Figure 1 A proposed 'hub and spoke' model for femtosecond laser-assisted cataract surgery.
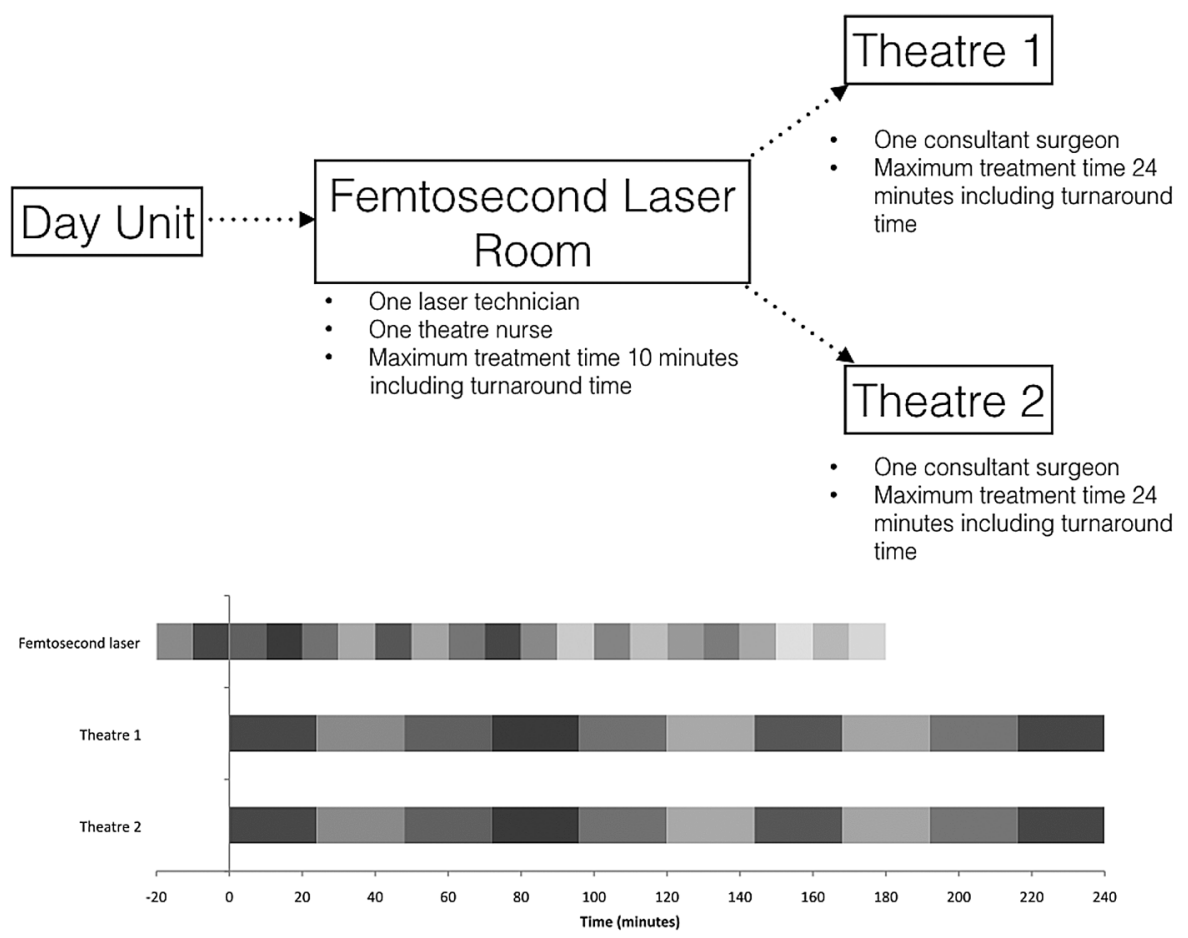
maximum of 24 min per case. These values are based on our own experience with the FL.

\section{Sensitivity analysis}

The model was constructed using Microsoft Excel (Microsoft Corp, Redmond, Washington, USA) based on the range of the above inputs (table 1). Univariate and bivariate sensitivity analyses were conducted by varying the inputs into the model to simulate the impact on the final service costs. The inputs chosen for the sensitivity analysis were as follows:

1. capital cost of the FL,

2. cost of the PI,

3. number of cases possible on a FLACS theatre list,

4. number of cases performed on a CPS list,

5. number of cataract operations required per week.

Threshold analyses were performed on the same variables as the sensitivity analyses to determine threshold values at which FLACS may break even with CPS. The results are reported as weekly costs.

\section{RESULTS}

The first model tested FLACS versus CPS based on an average number of seven cases currently performed on CPS cataract lists. Our model estimated that the current CPS service at its existing productivity was costing $£ 433$ per case. Using a model that incorporates one FL into one theatre list, and therefore assuming no increase in productivity, the laser increases the cost per case by $£ 167$ to $£ 600$. Based on these values, the CPS service would be $72 \%$ of the cost of a FLACS service.

Using the averaged and nominal values for our theoretical 'hub and spoke' model for FLACS, the use of the FL reduced the weekly theatre requirements from 8 CPS theatre sessions to 2.7 FLACS sessions with both theatres in the FL model running in parallel (total theatre sessions 5.4). This reduced the anticipated running costs of theatres, the ophthalmic day-case unit and staffing costs. However, the laser introduced additional costs into the model (FL equipment, supplies, maintenance and additional staff). Based on the nominal values, even with our hub and spoke model running optimally, the CPS service (average of $£ 433 /$ case) was found to be $86.3 \%$ of the cost of the FLACS service (average of $£ 502 /$ case).

The capital cost of the FL when amortised over its lifetime of 10 years was $£ 505 /$ week. Maintenance of the laser was $£ 545 /$ week. The cost of 1 week's worth of PI $(\mathrm{n}=55)$ at $£ 135$ each was $£ 7356$ (figure 2).

The model was not affected when we changed the salary of the laser operator from a midpoint registrar to a band 6 nurse as the hourly rates were of negligible difference (table 1).

Univariate sensitivity analyses were conducted by varying one variable at a time. Minimum and maximum values were obtained from the original data (table 2).

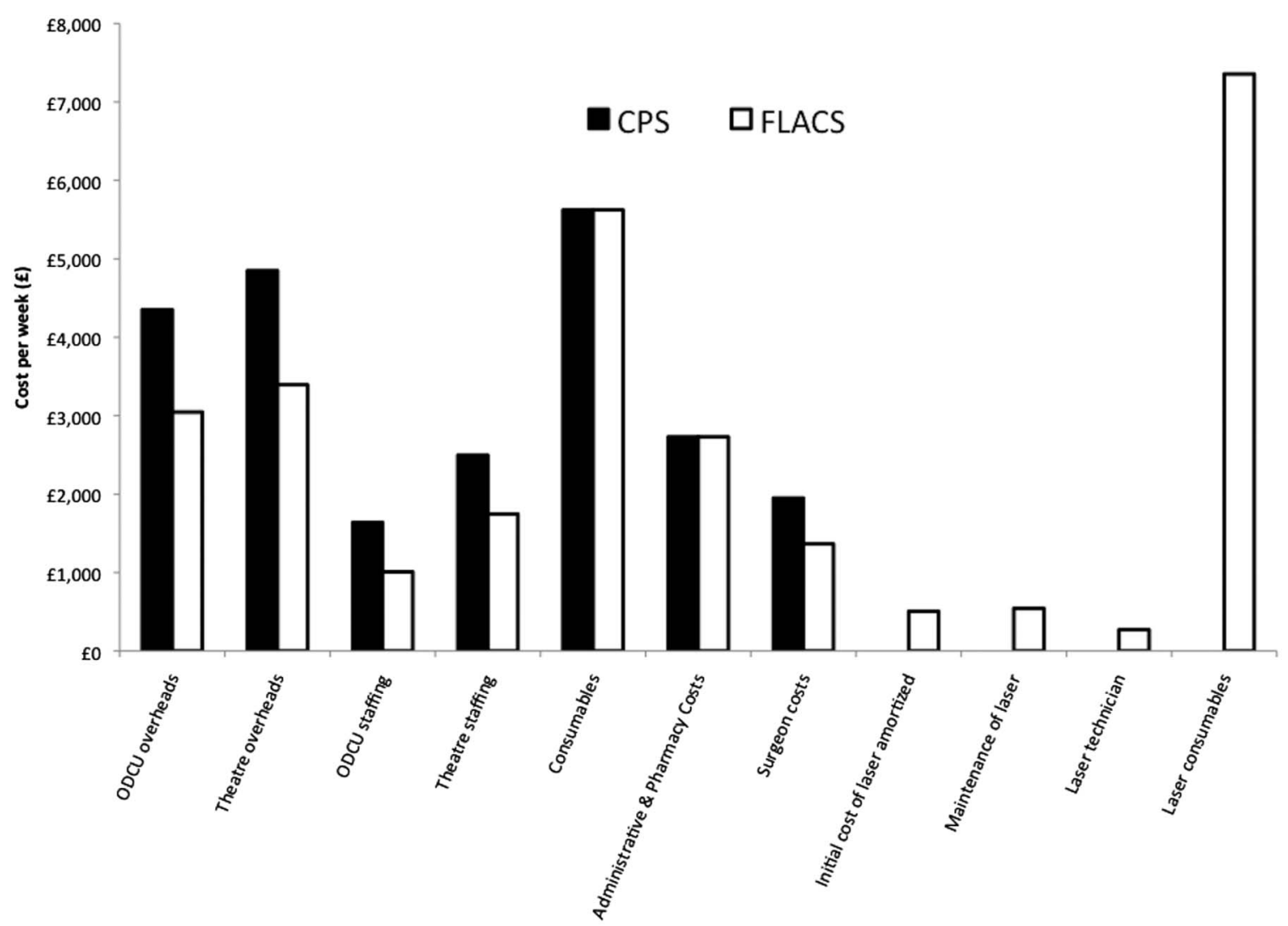

Figure 2 Comparison of the costs per week of conventional phacoemulsification surgery compared with femtosecond laser-assisted cataract surgery. 
Table 2 (A) Univariate sensitivity analysis of the hub and spoke model based on range of values from data collected and (B) best-case scenarios for conventional phacoemulsification surgery and femtosecond laser-assisted cataract surgery

\begin{tabular}{|c|c|c|c|c|c|c|c|}
\hline \multicolumn{2}{|l|}{ Input } & \multicolumn{2}{|c|}{ Range of values } & \multicolumn{2}{|c|}{$\begin{array}{l}\text { Values inputted } \\
\text { into hub and } \\
\text { spoke model }\end{array}$} & \multicolumn{2}{|c|}{$\begin{array}{l}\text { Cost of CPS service } \\
\text { compared with FLACS (\%) }\end{array}$} \\
\hline \multicolumn{8}{|l|}{$A$} \\
\hline \multirow{3}{*}{\multicolumn{2}{|c|}{$\begin{array}{l}\text { Cataract } \\
\text { workload/week }\end{array}$}} & & \multicolumn{2}{|l|}{27} & \multicolumn{2}{|l|}{82.7} \\
\hline & & \multirow{2}{*}{\multicolumn{2}{|c|}{$\begin{array}{l}\text { Average } \\
\text { Maximum }\end{array}$}} & \multicolumn{2}{|l|}{55} & \multicolumn{2}{|l|}{86.3} \\
\hline & & & & 96 & & 87.8 & \\
\hline \multicolumn{2}{|l|}{ Number of } & \multicolumn{2}{|l|}{ Minimum } & \multicolumn{2}{|l|}{5} & \multicolumn{2}{|l|}{108.5} \\
\hline \multirow{2}{*}{\multicolumn{2}{|c|}{$\begin{array}{l}\text { cataratets on } \\
\text { CPS list** }^{*}\end{array}$}} & \multicolumn{2}{|l|}{ Nominal } & \multicolumn{2}{|l|}{7} & \multicolumn{2}{|l|}{86.3} \\
\hline & & Maximum & & 9 & & \multicolumn{2}{|l|}{73.8} \\
\hline \multicolumn{2}{|l|}{ Number of } & Minimum & & 8 & & \multirow{2}{*}{\multicolumn{2}{|c|}{$\begin{array}{l}78.6 \\
86.3\end{array}$}} \\
\hline \multirow{2}{*}{\multicolumn{2}{|c|}{$\begin{array}{l}\text { cataracts on } \\
\text { FL listt }\end{array}$}} & \multicolumn{2}{|l|}{ Nominal } & \multicolumn{2}{|l|}{10} & & \\
\hline & & \multicolumn{2}{|l|}{ Maximum } & \multicolumn{2}{|l|}{16} & \multicolumn{2}{|l|}{100.8} \\
\hline \multirow{2}{*}{\multicolumn{2}{|c|}{$\begin{array}{l}\text { Initial cost of } \\
\text { FL }\end{array}$}} & \multicolumn{2}{|l|}{ Minimum } & \multicolumn{2}{|c|}{$£ 175000$} & \multicolumn{2}{|l|}{86.7} \\
\hline & & Average & & $£ 262$ & & 86.3 & \\
\hline & & Maximum & & $£ 350$ & & 85.7 & \\
\hline Cost of PI & & Minimum & & $£ 99$ & & 92.8 & \\
\hline & & Average & & $£ 135$ & & 86.3 & \\
\hline & & Maximum & & $£ 170$ & & 80.5 & \\
\hline & $\begin{array}{l}\text { Cataract } \\
\text { workload/ } \\
\text { week }\end{array}$ & $\begin{array}{l}\text { Number of } \\
\text { cataracts on } \\
\text { CPS list }\end{array}$ & $\begin{array}{l}\text { Number of } \\
\text { cataracts on } \\
\text { FL list }\end{array}$ & $\begin{array}{l}\text { Cost } \\
\text { of PI }\end{array}$ & $\begin{array}{l}\text { Cost of } \\
\text { CPS/case }\end{array}$ & $\begin{array}{l}\text { Cost of } \\
\text { FLACS/case }\end{array}$ & $\begin{array}{l}\text { Cost of CPS } \\
\text { service } \\
\text { compared with } \\
\text { FLACS (\%) }\end{array}$ \\
\hline$B$ & & & & & & & \\
\hline $\begin{array}{l}\text { Best-case } \\
\text { scenario for } \\
\text { CPS }\end{array}$ & 27 & 9 & 9 & 135 & $£ 371$ & $£ 515$ & 72.1 \\
\hline $\begin{array}{l}\text { Best-case } \\
\text { scenario for } \\
\text { FLACS }\end{array}$ & 96 & 5 & 10 & 50 & $£ 545$ & $£ 381$ & 143.2 \\
\hline
\end{tabular}

Only when the number of operations on a CPS list was reduced or the number of operations on a FLACS list was increased, could the model give an output in favour of FLACS. Best and worst-case scenarios were constructed for CPS and FLACS, by aligning the most important variables all in favour of one or other modality, with costs of $£ 371$ and $£ 515$ for CPS and $£ 381$ and $£ 545$ for FLACS, respectively (table 2B).

Univariate threshold analyses were performed to demonstrate the 'break-even' values of each input. Keeping all other inputs at their original values, the model could not find solutions by which the FL broke even when the capital cost of the FL or the number of operations performed per week was chosen. The costs of the services were equivalent if the true number of cases on a CPS list was 6 , or if the FL could increase productivity to 16 cases/each theatre, or if the cost of the laser consumables was reduced to $£ 66$. It was thereby ascertained that these three parameters are the most important in this model for determining a cost-neutral scenario for FLACS.

Bivariate sensitivity analyses were performed using combinations of the above inputs. For example, table 3 shows the outcomes of the model when the capacity for the number of cases on CPS and FLACS is simultaneously tested. It shows that the FLACS service would be required to approximately double the number of operations possible during a theatre list for FLACS to break even. Table 4 tests the outcome of the model based on an assumption that the NHS can negotiate lower PI costs based on the provision of a large number of operations per year. It shows that FLACS cannot break even unless the cost of the PI is significantly reduced (to approximately $£ 50$ per case). Table 5 compares the cost of the PI against the number of cases on a FLACS list.

\section{DISCUSSION}

We have designed a hypothetical treatment delivery model based on a 'hub and spoke' service and utilising FLACS to improve the efficiency of cataract surgery in terms of number of cases undertaken per operating list. We then tested our model with sensitivity and threshold analyses to allow for variations or uncertainties.

Even with our optimised delivery model, FLACS is still more expensive than CPS based on current estimates of costs. To break even, the incorporation of FLACS would 
Table 3 Cost of femtosecond laser-assisted cataract surgery versus conventional phacoemulsification surgery

\begin{tabular}{llrrrr}
\hline & \multicolumn{5}{l}{ Number of operations on CPS list (\%) } \\
\cline { 2 - 6 } Number of operations on FLACS list & $\mathbf{5}$ & $\mathbf{6}$ & $\mathbf{7}$ & $\mathbf{8}$ & $\mathbf{9}$ \\
\hline 8 & 99.0 & 87.1 & 78.6 & 72.3 & 79.3 \\
10 & $\mathbf{1 0 8 . 5}$ & 95.5 & 86.2 & 73.8 \\
12 & $\mathbf{1 1 5 . 9}$ & $\mathbf{1 0 2 . 0}$ & 92.1 & 84.7 & 78.9 \\
14 & $\mathbf{1 2 1 . 9}$ & $\mathbf{1 0 7 . 3}$ & 96.9 & 89.0 & 82.9 \\
16 & $\mathbf{1 2 6 . 8}$ & $\mathbf{1 1 1 . 6}$ & $\mathbf{1 0 0 . 8}$ & 92.6 & 86.3 \\
\hline
\end{tabular}

Bold indicates where FLACS is less expensive than CPS option.

Bivariate sensitivity analysis: demonstrating relative costs of CPS service compared with FLACS when total number of cases on each theatre list are tested.

Table 4 Cost of femtosecond laser-assisted cataract surgery versus conventional phacoemulsification surgery

\begin{tabular}{|c|c|c|c|c|c|}
\hline \multirow[b]{2}{*}{ Cost of PI (£) } & \multicolumn{5}{|c|}{ Number of cataract operations per year (\%) } \\
\hline & 2000 & 3000 & 4000 & 5000 & 6000 \\
\hline 50 & 101.5 & 104.0 & 105.2 & 106.0 & 106.5 \\
\hline 75 & 95.9 & 98.1 & 99.2 & 99.9 & 100.4 \\
\hline 100 & 90.9 & 92.8 & 93.8 & $94.4 \%$ & 94.9 \\
\hline 125 & 86.4 & 88.1 & 89.0 & 89.6 & 89.9 \\
\hline 150 & 82.3 & 83.8 & 84.7 & 85.2 & 85.5 \\
\hline
\end{tabular}

Bold indicates where FLACS is less expensive than CPS option.

Bivariate sensitivity analysis: demonstrating relative costs of CPS service compared with FLACS when cost of PI and total number of cases per year are tested.

Table 5 Cost of femtosecond laser-assisted cataract surgery versus conventional phacoemulsification surgery

\begin{tabular}{|c|c|c|c|c|c|c|}
\hline \multirow[b]{2}{*}{ Cost of PI } & \multicolumn{6}{|c|}{ Number of operations on FLACS list (\%) } \\
\hline & 8 & 9 & 10 & 12 & 14 & 16 \\
\hline 50 & 92.9 & 98.6 & 103.7 & 112.4 & 119.5 & 125.5 \\
\hline 65 & 90.0 & 95.4 & 100.1 & 108.2 & 114.8 & 120.3 \\
\hline 80 & 87.3 & 92.3 & 96.7 & 104.3 & 110.4 & 115.5 \\
\hline 100 & 83.9 & 88.5 & 92.6 & 99.5 & 105.0 & 109.6 \\
\hline 120 & 80.8 & 85.1 & 88.8 & 95.1 & 100.2 & 104.3 \\
\hline 135 & 78.6 & 82.6 & 86.2 & 92.1 & 96.8 & 100.7 \\
\hline
\end{tabular}

have to approximately double the number of cataract operations performed per theatre list and indeed could not offer a cost-neutral solution if the number of cases on a CPS theatre list was 8 or more. Our model indicates that the greatest cost impediment to a FLACS service is the price of the PI (average cost $£ 135 /$ case) (figure 2), which represents almost $27 \%$ of the total cost per case. Unlike other service costs, the cost of the PI is not mitigated by potential increased productivity. It is therefore a major financial impediment to FLACS ever becoming cost-effective within the NHS, where the total tariff for each operation is fixed between $£ 718$ and $£ 932 .{ }^{16} 17$ Potentially, this problem may be overcome by the manufacturer considerably discounting this cost to the NHS. In contrast to the PI, our financial model indicates that the costs of the laser itself, staffing and maintenance it were much less important ( $4.8 \%$ of total costs).

There are three important unknowns with regard to our model. First, we are awaiting clinical results from large RCTs comparing FLACS with CPS. ${ }^{11}{ }^{12}$ The latest meta-analysis shows no significant advantages in terms of safety of FLACS over CPS. ${ }^{10}$ However, there are advantages in terms of endothelial cell loss, effective phacoemulsification time and unaided visual acuity, albeit no difference in long-term best-corrected visual acuity and an increased risk of anterior capsular tear. ${ }^{18}$ We assumed in our financial modelling that there are no differences in outcomes and complication rates between the two procedures. If, however, FLACS were to show significant advantages in terms of patient safety and outcomes then such improvements then this may have additional positive financial implications.

Second, potential gains in productivity from the FL are as yet unpublished and unrealised. Several studies investigating FLACS actually report decreased patient turnover with FLACS. ${ }^{13} 1920$ This is because at present typically the operating surgeon is performing the FL treatment as well as the subsequent lens extraction. 
There are as yet no publications on the most effective way to design a FL-centric cataract service. We chose a 'hub and spoke' model based on one FL in a clean room, operated by an ophthalmic surgeon in training or ophthalmic technician/nurse. The FL then fed patients into two independent operating theatres, each with its own surgeon and support staff. This model is theoretical. It needs to be tested in the NHS setting to see if it is viable, and further work may need to be performed to determine a 'best-practice' and optimised efficiency model for FLACS.

Third, it is likely that the costs of the PIs would be reduced below the values quoted to us by the manufacturers, as a large public sector ophthalmology department performing several thousand operations per year could negotiate on costs and capitalise on market competition. As discussed above, this would considerably improve the financial burdens associated with implementing FLACS.

Abell and Vote ${ }^{13}$ have previously designed a hypothetical model to derive cost-effectiveness of FLACS. In the absence of better evidence, conservative estimates were used for complication rates with FLACS. Their use of the FL resulted in reducing their theatre efficiency by two cases per list, and subsequently, they estimated the additional cost of FL to be AUS $\$ 1065$ per case, AUS $\$ 750$ of which were the direct costs from the FL and AUS $\$ 315$ from lost productivity. Our model was based on using the laser to improve, rather than impede, productivity. We estimated the cost per case to be $£ 158$, of which $£ 135$ is the PI. We chose to amortise the costs of the laser over 10 years rather than only 3 , but reducing the lifetime of the laser to 3 years increased the cost of each operation to only $£ 180$. This demonstrates yet again the greatest cost of FLACS is the cost of the PI rather than the laser itself.

In addition to the above, there are important limitations to mention regarding this hypothetical model. The model assumes that all patients are suitable for a high-volume FLACS theatre list. However, some patients may not be suited to FLACS or to a high-volume service, although the number of contraindications for FLACS is decreasing as experience with the technology improves. $^{21-23}$

Departmental costs used in this model were obtained from a retrospective review of the financial records at four NHS foundation trusts. In order to ensure that the results were applicable to more than just one hospital with its associated population, we selected two teaching hospitals and two district general hospitals of varying sizes, with annual numbers of between $\sim 1400$ and 5000 cataract operations. These hospitals serve urban and rural populations (range $\sim 275000-823000$ served by each hospital) with a mixture of demographics (and include hospitals with one of the highest and one of the lowest cataract tariffs). ${ }^{17}$

The costs of consumables were assumed to be equal for FLACS and CPS. In reality, as the FL performs many stages of the procedure, the cost of some consumables may be reduced (vision blue, cystotome, etc) and some cataracts may no longer require any phacoemulsification. ${ }^{24}$ Our model incorporates the salary of a registrar to operate the laser, ${ }^{25}{ }^{26}$ yet if FLACS becomes widely adopted within the UK, then technicians may be trained to perform this duty, perhaps at a reduced cost, but no money was saved when we modelled for the salary of a band 6 nurse to operate the laser.

Overall, this model demonstrates that FLACS could only be financially viable if its implementation into the NHS allowed significant improvements in efficiency in the number of cases treated per theatre list and/or if the cost of the PI was considerably reduced. Further research is required on the clinical outcomes of FLACS compared with CPS as well as real-world evidence of the effect to surgical efficiency afforded by this technology.

Acknowledgements Guy's and St Thomas' NHS Foundation Trust, Norfolk and Norwich NHS Foundation Trust, Peterborough and Stamford NHS Foundation Trust and West Suffolk NHS Foundation Trust; Abbott Medical Optics, Santa Ana, California, USA; Ziemer Ophthalmic Systems AG, Switzerland; Alcon Laboratories, Fort Worth, Texas, USA and Bausch \& Lomb, Rochester, New York, USA; Karen Bateman.

Contributors HWR, MZN and DPSOB contributed to acquisition of data, analysis and interpretation of data, drafting the article and revising it critically for important intellectual content.

Funding This research has been supported by a non-commercial research grant from Alcon Incorporated.

Competing interests None declared.

Provenance and peer review Not commissioned; externally peer reviewed.

Data sharing statement Further information is available by emailing HWR (harry.roberts@nhs.net).

Open Access This is an Open Access article distributed in accordance with the Creative Commons Attribution Non Commercial (CC BY-NC 4.0) license, which permits others to distribute, remix, adapt, build upon this work noncommercially, and license their derivative works on different terms, provided the original work is properly cited and the use is non-commercial. See: http:// creativecommons.org/licenses/by-nc/4.0/

\section{REFERENCES}

1. Department of Health. HES online Health Episode Statistics. 2015 https://www.google.co.uk/url?sa=t\&rct=j\&q=\&esrc=s\&source=web\& $c d=1 \&$ ved=0ahUKEwjg2-211 cfSAhXJDywKHQSxCpUQFggaMAA \&url=http $\% 3 \mathrm{~A} \% 2 \mathrm{~F} \% 2 \mathrm{~F}$ content.digital.nhs.uk\%2Fcatalogue $\% 2 \mathrm{FPU}$ B19124\%2Fhosp-epis-stat-admi-proc-2014-15-tab.xlsx\&usg=AFQ] CNFyjQSbEQpRdDNHEpJrqBrClJNaJg\&sig2=NPzSII2T6rr-QODx Hk3BPQ\&bvm=bv.149093890,d.bGg. (Last accessed 8th March 2017)

2. Black N, Browne J, van der Meulen J, et al. Is there overutilisation of cataract surgery in England? Br J Ophthalmol 2008;93:13-17.

3. Minassian DC, Reidy A. Future sight loss UK (2): an epidemiological and economic model for sight loss in the decade 2010-2020. 2009:1-130. http://www.rnib.org.uk/sites/default/files/FSUK_2.pdf (accessed 25 Oct 2016).

4. Nagy Z, Takacs A, Filkorn T, et al. Initial clinical evaluation of an intraocular femtosecond laser in cataract surgery. J Refract Surg 2009;25:1053-60.

5. Ewe SY, Abell RG, Oakley CL, et al. A comparative cohort study of visual outcomes in femtosecond laser-assisted versus phacoemulsification cataract surgery. Ophthalmology 2016;123:178-82.

6. Chee SP, Yang Y, Ti SE. Clinical outcomes in the first two years of femtosecond laser-assisted cataract surgery. Am J Ophthalmol 2015;159:714-19.e2. 
7. Abell RG, Kerr NM, Vote BJ. Femtosecond laser-assisted cataract surgery compared with conventional cataract surgery. Clin Exp Ophthalmol 2013;41:455-62.

8. Abell RG, Darian-Smith E, Kan JB, et al. Femtosecond laser-assisted cataract surgery versus standard phacoemulsification cataract surgery: outcomes and safety in more than 4000 cases at a single center. J Cataract Refract Surg 2015;2015:47-52.

9. Roberts TV, Lawless M, Bali SJ, et al. Surgical outcomes and safety of femtosecond laser cataract surgery: a prospective study of 1500 consecutive cases. Ophthalmology 2013;120:227-33.

10. Chen X, Xiao W, Ye S, et al. Efficacy and safety of femtosecond laser-assisted cataract surgery versus conventional phacoemulsification for cataract: a meta-analysis of randomized controlled trials. Sci Rep 2015;5:13123.

11. Schweitzer C, Hayes N, Brezin A, et al. Re: Abell et al.: Cost-effectiveness of femtosecond laser-assisted cataract surgery versus phacoemulsification cataract surgery (Ophthalmology 2014:121:10-6). Ophthalmology 2014;121:e53-4.

12. Day AC, Burr JM, Bunce $C$, et al. Randomised, single-masked non-inferiority trial of femtosecond laser-assisted versus manual phacoemulsification cataract surgery for adults with visually significant cataract: the FACT trial protocol. BMJ Open 2015;5: e010381.

13. Abell RG, Vote BJ. Cost-effectiveness of femtosecond laser-assisted cataract surgery versus phacoemulsification cataract surgery. Ophthalmology 2014:121:10-16.

14. Hansen MS, Hardten DR. Financially efficient cataract surgery in today's healthcare environment. Curr Opin Ophthalmol 2015;26:61-5.

15. Bartlett JD, Miller KM. The economics of femtosecond laser-assisted cataract surgery. Curr Opin Ophthalmol 2016;27:76-81.

16. Department of Health. 2015-16-eto-spreadsheet-3. 2016. https:// www.google.co.uk/url?sa=t\&rct=j\&q=\&esrc=s\&source $=$ web\&cd $=1 \&$ ved=0ahUKEwiYsoPOi9rNAhWMLsAKHcKfCaUQFggeMAA\&url= https $\% 3 \mathrm{~A} \% 2 \mathrm{~F} \% 2 \mathrm{Fwww}$.england.nhs.uk\%2Fwp-content $\% 2 \mathrm{Fuploads}$ \%2F2015\%2F03\%2F2015-16-eto-spreadsheet. xlsx\&usg=AFQjCNHr4y_QdTX6KyU96-knpRLOAHcyLQ\&sig2=6Z6D9BLQpmdZcpuXAadog (accessed 25 Oct 2016).
17. Department of Health. 2015-16-eto-guid-market-forces-payment-4. 2016. https://www.google.co.uk/url?sa=t\&rct=j\&q=\&esrc=s\& source $=$ web\&cd $=1 \& v e d=0$ ahUKEwj3k-GBjdrNAhWYHsAKHRp2 ARgQFggeMAA\&url=https\%3A\%2F\%2Fwww.england.nhs.uk\% 2Fwp-content\%2Fuploads\%2F2015\%2F03\%2F2015-16-eto-guidmarket-forces-payment.

xlsx\&usg=AFQjCNFV4OKenNMsJOJuXIPSoFgkKaSelw\& sig2=SIcpHBWBquHKVoxxBalk7g (accessed 25 Oct 2016)

18. Kohnen T, Mathys L, Petermann K, et al. Metaanalysis and systematic review of femtosecond laser lens surgery and conventional lens surgery. Copenhagen: European Society of Cataract and Refractive Surgeons, 2016.

19. Bali SJ, Hodge C, Lawless M, et al. Early experience with the femtosecond laser for cataract surgery. Ophthalmology 2012;119:891-9.

20. Lubahn JG, Donaldson KE, Culbertson WW, et al. Operating times of experienced cataract surgeons beginning femtosecond laser-assisted cataract surgery. J Cataract Refract Surg 2014;40:1773-6.

21. Conrad-Hengerer I, Hengerer FH, Joachim SC, et al. Femtosecond laser-assisted cataract surgery in intumescent white cataracts. $J$ Cataract Refract Surg 2014;40:44-50.

22. Dick HB, Schultz T. Femtosecond laser-assisted capsulotomy rescue for capsulorhexis enlargement. $J$ Cataract Refract Surg 2014;40:1588-90.

23. Hatch KM, Schultz T, Talamo JH, et al. Femtosecond laser-assisted compared with standard cataract surgery for removal of advanced cataracts. J Cataract Refract Surg 2015;41:1833-8.

24. Abell RG, Kerr NM, Vote BJ. Toward zero effective phacoemulsification time using femtosecond laser pretreatment. Ophthalmology 2013;120:942-8.

25. Cohen MN, Intili A, Ni N, et al. Femtosecond laser-assisted cataract surgery in residency training. Curr Opin Ophthalmol 2015:26:56-60.

26. Hou JH, Prickett AL, Cortina MS, et al. Safety of femtosecond laser-assisted cataract surgery performed by surgeons in training. $\checkmark$ Refract Surg 2015;31:69-70. 